\title{
Diagnostic Performance of Shear Wave Elastography Ultrasound for Identification of Esophageal Varices Needing Treatment in Initially Diagnosed Patients of Compensated Cirrhotic Liver
}

\author{
Wael Abdelghany ${ }^{1}$, Mahmoud M. Higazi* ${ }^{2}$, Elham Mousa ${ }^{1}$, Mahmoud R. Mohamed ${ }^{3}$, Wafaa Abdelhamid ${ }^{1}$ \\ Departments ${ }^{1}$ Tropical Medicine, ${ }^{2}$ Radiology and ${ }^{3}$ Internal Medicine, Faculty of Medicine, Minia University, Egypt \\ *Corresponding author: Mahmoud M. Higazi, E-Mail: mahmoud.higazi@ minia.edu.eg
}

\begin{abstract}
Background: The presence of varices in liver cirrhosis patients is an important risk factor for death and decompensation. Ultrasound elastography can be a noninvasive alternative to estimate portal hypertension severity and to predict varices.

Objective: Our study was performed to evaluate the diagnostic performance of liver stiffness (LS) and splenic stiffness (SS) measured by 2D shear wave elastography (SWE) and correlate it with endoscopic findings for the accuracy of assessment of varices needing treatment (VNT) in compensated liver cirrhosis patients.

Patients and methods: This is a prospective study that included 150 patients who had compensated liver cirrhosis. Two dimensional shear wave elastography measurements for liver and spleen stiffness were obtained and upper gastrointestinal endoscopies for the presence and grade of varices were performed.

Results: We found that as liver or spleen stiffness increases, the more is the increase in the size of the varices with significant positive linear correlation ( $p$ value $<0.001$ ). We tried to identify the value of liver/spleen stiffness, which could predict presence of significant varices. Multivariate analysis identified several factors that could be associated with high risk varices, including liver and spleen elastography ( $\mathrm{p}<0.001)$.

Conclusion: Shear wave elastography is an effective and noninvasive tool not only for staging of fibrosis, but also for predicting clinically significant portal hypertension.

Keywords: Shear Wave Elastography Ultrasound, Esophageal Varices, Compensated Cirrhotic Liver.
\end{abstract}

\section{INTRODUCTION}

Cirrhotic liver patients can be divided into compensated and decompensated disease, which have substantially different prognoses. Although more difficult to detect clinically, compensated cirrhosis has a better prognosis, and early treatment may prevent progression and complications (1). Upper gastrointestinal (GI) bleeding from varices is a common complication of portal hypertension due to chronic liver disease and carries a high mortality rate of about 20 $35 \%$ (2).

Patients with compensated cirrhosis and clinically significant PHT are at a higher risk of varices, decompensation, and hepato-cellular carcinoma (HCC). The presence of varices is an important risk factor for death and decompensation. Therefore, being able to detect varices as early as possible has the potential to affect patient outcome ${ }^{(3)}$.

The standard method for evaluating portal hypertension is hepatic venous pressure gradient (HVPG) measurement and the stratification of variceal bleeding is mainly based on endoscopy ${ }^{(4)}$. However; ultrasound elastography could be a noninvasive alternative to estimate portal hypertension severity and to predict varices ${ }^{(5)}$. Shear wave elastography is based upon generation of shear waves induced by the force of a focused ultrasound beam. They travel slowly (between 1 and $10 \mathrm{~m} / \mathrm{s}$ ) and are attenuated by tissue. The propagation velocity of the shear waves correlates with elasticity of examined tissue ${ }^{\left({ }^{6}\right)}$.
Our study was performed to evaluate the diagnostic performance of liver stiffness (LS) and splenic stiffness (SS) measured by 2D shear wave elastography (SWE) and to correlate it with endoscopic findings for accuracy of non-invasive assessment of varices needing treatment (VNT) in compensated liver cirrhosis patients.

\section{PATIENTS AND METHODS:}

This is a prospective study included 150 patients who had chronic hepatitis, attended the Outpatient Clinic of the Tropical Medicine Department, Faculty of Medicine, Minia University Hospital. The patients were allocated into 2 groups according to the upper GIT endoscopy findings. The $1^{\text {st }}$ group included patients with no or minimal varices not needing treatment (VNNT). The $2^{\text {nd }}$ group included patients with varices needing treatment (VNT).

\section{Inclusion criteria:}

(1) Patients who are initially diagnosed as compensated liver cirrhosis due to HCV or HBV, (2) No beta blocker treatment and (3) Time interval between SWE and endoscopy $<30$ days.

\section{Exclusion criteria:}

Patients were excluded if they had previous decompensation manifested by hepatic encephalopathy or moderate/marked ascites, or if they had hepatocellular carcinoma. 
The control participants were healthy volunteers without any kind of liver disease, and having normal liver serologic results as well as normal liver sonographic findings.

\section{Ethical approval:}

An approval of the study was obtained from Minia University academic and ethical committee. Every patient signed an informed written consent for acceptance of the operation.

\section{Elastography:}

Patients were asked to fast for 4-6 hours before US elastography, as food intake can increase the liver stiffness value. Real-time shear wave elastography was done using a (Toshiba Aplio 500) ultrasound machine. For each patient, liver/spleen stiffness was defined as the mean of several SWE successful measurements.

Right lobe measurements using an inter-costal approach were obtained for liver stiffness measurement. Elastography measurements were acquired while the patients were in a supine position with their right arm in maximum abduction to widen spaces between ribs. The measurements were acquired during breath-hold at the end of expiration. The measurement depth was adjusted at about $3 \mathrm{~cm}$ depth under liver capsule. For each acquisition, real-time SWE 2D color map of the stiffness (in $\mathrm{m} / \mathrm{s}$ ) was frozen after a stabilization of at least 3 seconds. The size of the SWE color box was about $3 \times 4 \mathrm{~cm}$. The regions of interest (ROI) were performed in a 1.6- to 3-cm-diameter.

Spleen stiffness was measured while the patients were lying in right lateral decubitus position and their left arms were abducted. The location of the region of interest was in the middle portion of the spleen, about $2 \mathrm{~cm}$ below the splenic capsule. Two or 3 measurements were made during each breath-hold.

\section{Upper Endoscopy:}

Eighty-five patients with chronic liver disease were willing to undergo upper Oesophago-GastroDuodenoscopy (EGD), and they were examined under intravenous anesthesia using a GIF-XQ-2400 endoscope (Olympus Optical Co, Ltd, Tokyo, Japan). The endoscopic procedures were performed by a single operator with 10 years of experience in endoscopy.

The patients were classified as follows: 1) Patients with no varices or with low risk varices (of less than $5 \mathrm{~mm}$ and no signs of high-risk stigmata) and 2) Patients with high risk varices (either large varices of more than $5 \mathrm{~mm}$ thickness or displaying any signs of a high-risk of bleeding: red wales, cherry red spots or any gastric varices).

\section{Serum Biochemical Markers:}

Venous blood samples were taken from all positive participants after an overnight fast (8-12 hours) on the same day of SWE measurements. The samples were tested at the same laboratory for aspartate aminotransferase (AST), alanine aminotransferase (ALT) levels and platelet count. Aspartate-to-platelet $(\mathrm{A} / \mathrm{P})$ ratios were calculated.

\section{Statistical Analysis}

SPSS version 20 was used. The quantitative variables were tested for normality by KolmogrovSmirnov test. The descriptive data was expressed as mean, median, range, and SD. The independent t-test was used for comparison of binary groups with normal distribution variables, and a Mann-Whitney test was used for comparison of binary groups with non-normal distribution variables. Chi-square test was used for comparison of qualitative data. One way ANOVA test was used for comparison of more than two groups with normal distribution variables and a Kruskal-Wallis test was used for comparison of more than two groups with non-normal distribution variables. Correlation analysis was performed with a Spearman's correlation test. Receiver-operating characteristic (ROC) curve was performed for diagnostic accuracy of liver stiffness and spleen stiffness. Statistical significance was defined as a $\mathrm{P}$ value $\leq 0.05$

\section{RESULTS}

A total of 150 consecutive patients who were initially diagnosed as compensated liver cirrhosis were recruited from attendants of Tropical Medicine Clinic. The diagnosis was based upon clinical assessment, abdominal ultrasonography, liver function tests, and serologic hepatitis markers. The patients underwent 2D shear wave elastography (2 D SWE) to determine the degree of stiffness of the liver and spleen tissues. The patients were examined by upper gastrointestinal endoscopy (within 30 days of SWE examination) with special emphasis on the presence or absence of varices and degree of varices.

They were 77 (51\%) females. Their ages ranged between 30 to 75 years old. The etiology of liver cirrhosis was HBV in 30 patients $(20 \%)$ and $\mathrm{HCV}$ in 120 patients $(80 \%)$. The demographic as well as baseline clinical and laboratory data of enrolled patients are shown in (Table 1).

Shear wave elastography examination revealed that 57 patients $(38 \%)$ were F1, 43 (29\%) were F2, 23 (15\%) were F3 and 27 (18\%) were F4 according to Metavir scoring system.

The patients were allocated into 2 groups according to the upper GIT endoscopy findings). The $1^{\text {st }}$ group included 63 patients $(42 \%)$ with high risk varices, i.e., varices needing treatment (VNT). They were 36 male $(42 \%)$ and their mean age was $57 \pm 8$ years. The $2^{\text {nd }}$ group included 87 patients $(58 \%)$ who had low risk varices (No VNT). They were $82(55 \%)$ males with mean age of $54 \pm 11$ years. We found a significant difference between low and high risk groups regarding $F$ stage ( $\mathrm{p}$ value $<0.001$ ). By analyzing the 
shear wave elastography findings for the high risk group, we found that liver stiffness and spleen stiffness were significantly higher among the high risk group.

There was direct correlation found between degree of liver stiffness and varix grade $(r=0.85 ; \rho=$ $0.001)$ as well as spleen stiffness and varix grade $(r=$ $0.73 ; \rho=0.001)$. Thus, as liver or spleen stiffness is increasing, there is a significant increase of the risk of the varices.

We tried to find cut-off values above which patients with compensated chronic liver disease could have significant varices (Table 2). For a cut-off value of $2.4 \mathrm{~m} / \mathrm{s}$, liver stiffness measurement by SWE had $75 \%$ sensitivity and $70 \%$ specificity, $71 \% \mathrm{PPV}$, and $73 \%$ NPV. Regarding spleen stiffness, a cut-off value of $3.6 \mathrm{~m} / \mathrm{s}$ had $87.5 \%$ sensitivity, $82.6 \%$ specificity, 83.4 $\%$ PPV and $86.8 \%$ NPV. Multivariate analysis revealed that decreased AP ratio ( $\mathrm{p}$ value $=0.001$ ), increased liver elastography $(\mathrm{p}<0.001)$, and increased spleen elastography ( $\mathrm{p}$ value $<0.001$ ), were associated with significant varices (VNT), as listed in (Table 3). ROC curves are shown by figures (1) and (2).Illustrative examples are shown in Figures (3), (4), and (5).

Table (1): The comparison between VNT and non-VNT groups regarding different descriptive data, laboratory investigations and imaging parameters

\begin{tabular}{|c|c|c|c|}
\hline & VNT $(42 \%)$ & No VNT $(58 \%)$ & P value \\
\hline $\begin{array}{l}\text { Age (years) } \\
\text { Mean } \pm \text { SD } \\
\text { Median }\end{array}$ & $\begin{array}{c}57 \pm 8 \\
55\end{array}$ & $\begin{array}{c}54 \pm 11 \\
55\end{array}$ & 0.1 \\
\hline $\begin{array}{l}\text { Liver stiffness }(\mathbf{m} / \mathbf{s}) \\
\text { Mean } \pm \text { SD } \\
\text { Median }\end{array}$ & $\begin{array}{c}3.4 \pm 1.14 \\
3.1\end{array}$ & $\begin{array}{c}1.8 \pm 0.42 \\
1.73\end{array}$ & $0.0001 *$ \\
\hline $\begin{array}{l}\text { Spleen stiffness }(\mathbf{m} / \mathbf{s}) \\
\text { Mean } \pm \text { SD } \\
\text { Median } \\
\text { Range }\end{array}$ & $\begin{array}{c}3.72 \pm 0.94 \\
3.86\end{array}$ & $\begin{array}{c}2.65 \pm 0.64 \\
2.76\end{array}$ & $0.0001 *$ \\
\hline $\begin{array}{l}\text { AST (IU/L) } \\
\text { Mean } \pm \text { SD } \\
\text { Median }\end{array}$ & $\begin{array}{c}73.6 \pm 2.1 \\
69\end{array}$ & $\begin{array}{c}39.6 \pm 6.9 \\
35\end{array}$ & $0.0001 *$ \\
\hline $\begin{array}{l}\text { ALT (IU/L) } \\
\text { Mean } \pm \text { SD } \\
\text { Median } \\
\text { Range } \\
\end{array}$ & $\begin{array}{c}47.2 \pm 5.4 \\
34.5 \\
17-105 \\
\end{array}$ & $\begin{array}{c}35.2 \pm 6.2 \\
30\end{array}$ & $0.04 *$ \\
\hline $\begin{array}{l}\text { AP ratio } \\
\text { Mean } \pm \text { SD } \\
\text { Median }\end{array}$ & $\begin{array}{c}0.78 \pm 0.42 \\
0.64\end{array}$ & $\begin{array}{c}0.23 \pm 0.22 \\
0.12 \\
0.07-0.9\end{array}$ & $0.0001 *$ \\
\hline $\begin{array}{l}\text { Albumin }(\mathbf{g} / \mathbf{d l}) \\
\text { Mean } \pm \text { SD } \\
\text { Median }\end{array}$ & $\begin{array}{c}3.2 \pm 0.5 \\
3.2\end{array}$ & $\begin{array}{c}3.8 \pm 0.7 \\
3.8\end{array}$ & $0.004 *$ \\
\hline $\begin{array}{l}\text { TB }(\mathbf{m g} / \mathbf{d l}) \\
\text { Mean } \pm \text { SD } \\
\text { Median }\end{array}$ & $\begin{array}{c}1.33 \pm 0.5 \\
1\end{array}$ & $\begin{array}{c}0.84 \pm 0.15 \\
0.79\end{array}$ & 0.05 \\
\hline $\begin{array}{l}\text { AFP } \\
\text { Mean } \pm \text { SD } \\
\text { Median }\end{array}$ & $\begin{array}{c}9.9 \pm 1.4 \\
5.7\end{array}$ & $\begin{array}{c}6.33 \pm 1.5 \\
4.6\end{array}$ & 0.3 \\
\hline
\end{tabular}

$\mathrm{P}$ values calculated by independent samples t-test for all variables except for ALT, INR, TB, albumin and AFP calculated by Mann-Whiney test $(<0.05$ is considered significant, $<0.001$ is considered highly significant). 
Table (2): Liver stiffness and spleen stiffness as predictors for VNT

\begin{tabular}{|c|c|l|l|l|l|l|l|l|}
\hline & AUC & P value & $\mathbf{9 5 \%}$ CI & $\begin{array}{c}\text { Cutoff } \\
\text { value }\end{array}$ & Sensitivity & Specificity & PPV & NPV \\
\hline $\begin{array}{c}\text { Liver } \\
\text { stiffness }\end{array}$ & 0.94 & $<0.0001$ & $0.89-0.99$ & 3.06 & $87.5 \%$ & $78.3 \%$ & $80 \%$ & $86.2 \%$ \\
\hline $\begin{array}{c}\text { Spleen } \\
\text { stiffness }\end{array}$ & 0.81 & $<0.0001$ & $0.7-0.92$ & 2.1 & $75 \%$ & $70 \%$ & $71 \%$ & $73 \%$ \\
\hline
\end{tabular}

Table (3): Multiple regression analysis for factors affecting VNT

\begin{tabular}{|l|c|c|}
\hline & OR $(\mathbf{9 5 \%}$ CI) & P value \\
\hline Liver stiffness & $3.921(0.825-7.54)$ & $<0.001$ \\
\hline Spleen stiffness & $2.364(0.8-2.18)$ & $<0.001$ \\
\hline AP ratio & $0.05(0.001-3.87)$ & 0.05 \\
\hline AST & $1.05(0.095-1.18)$ & 0.3 \\
\hline PLT & $0.96(0.91-1.01)$ & 0.1 \\
\hline
\end{tabular}

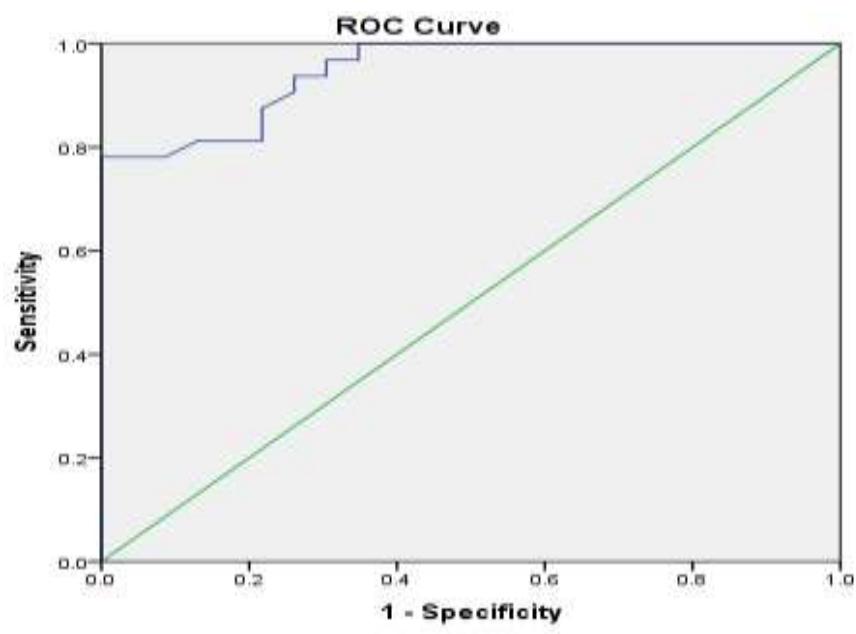

Fig. (1): ROC curve for diagnostic performance of liver stiffness for prediction of high risk esophageal varices.

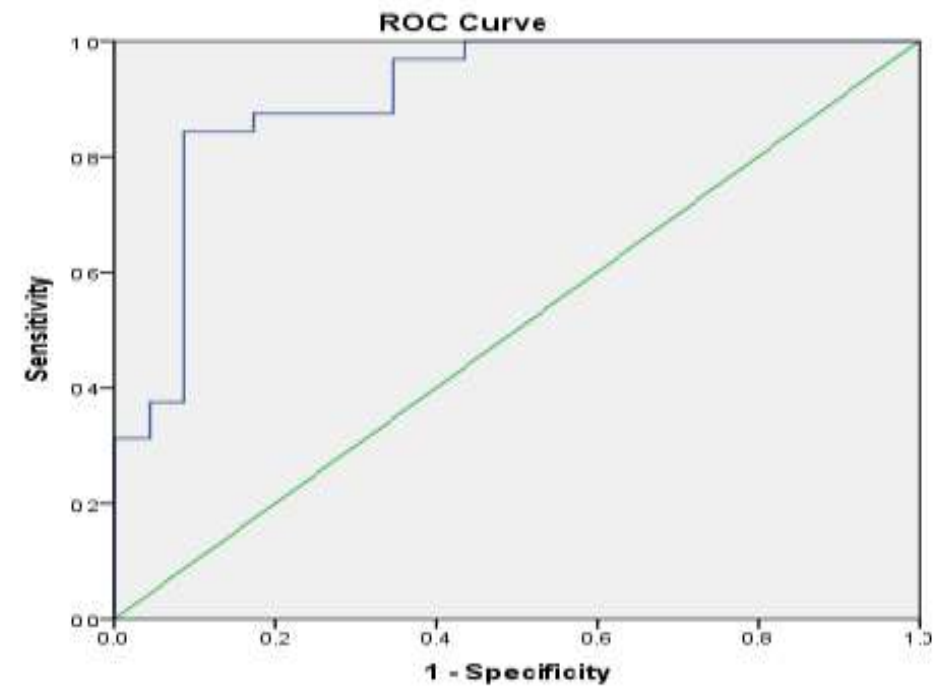

Fig. (2): ROC curve for diagnostic performance of spleen stiffness for prediction of high risk esophageal varices. 


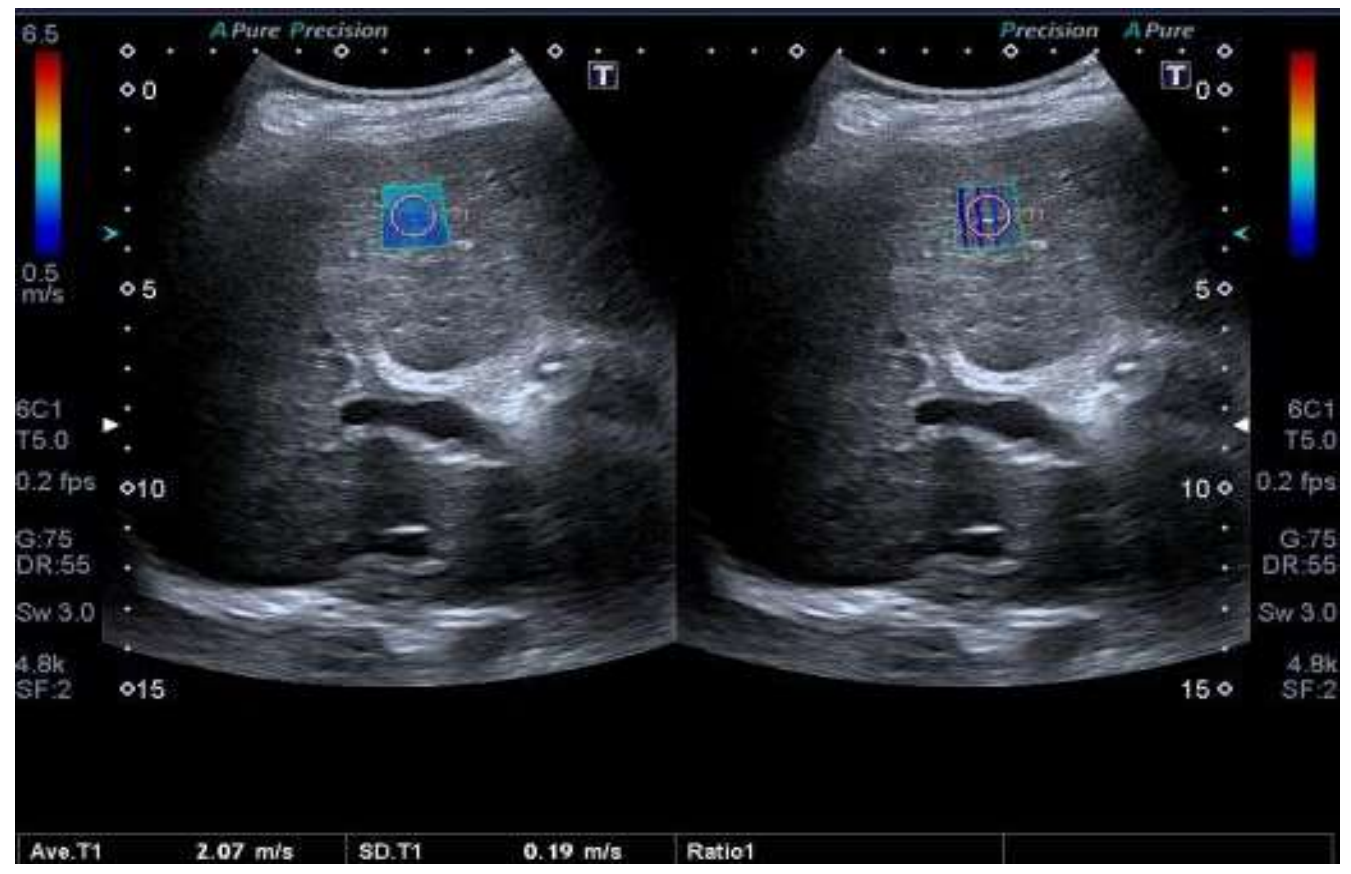

Fig. (3): A 65-year-old patient with chronic hepatitis C. Normal ultrasound features of liver parenchyma. 2D shear wave elastography revealed a liver stiffness of $2.07 \mathrm{~m} / \mathrm{s} \pm 0.19$ (F2 according to Metavir scoring). No esophageal varices were identified by endoscopy.

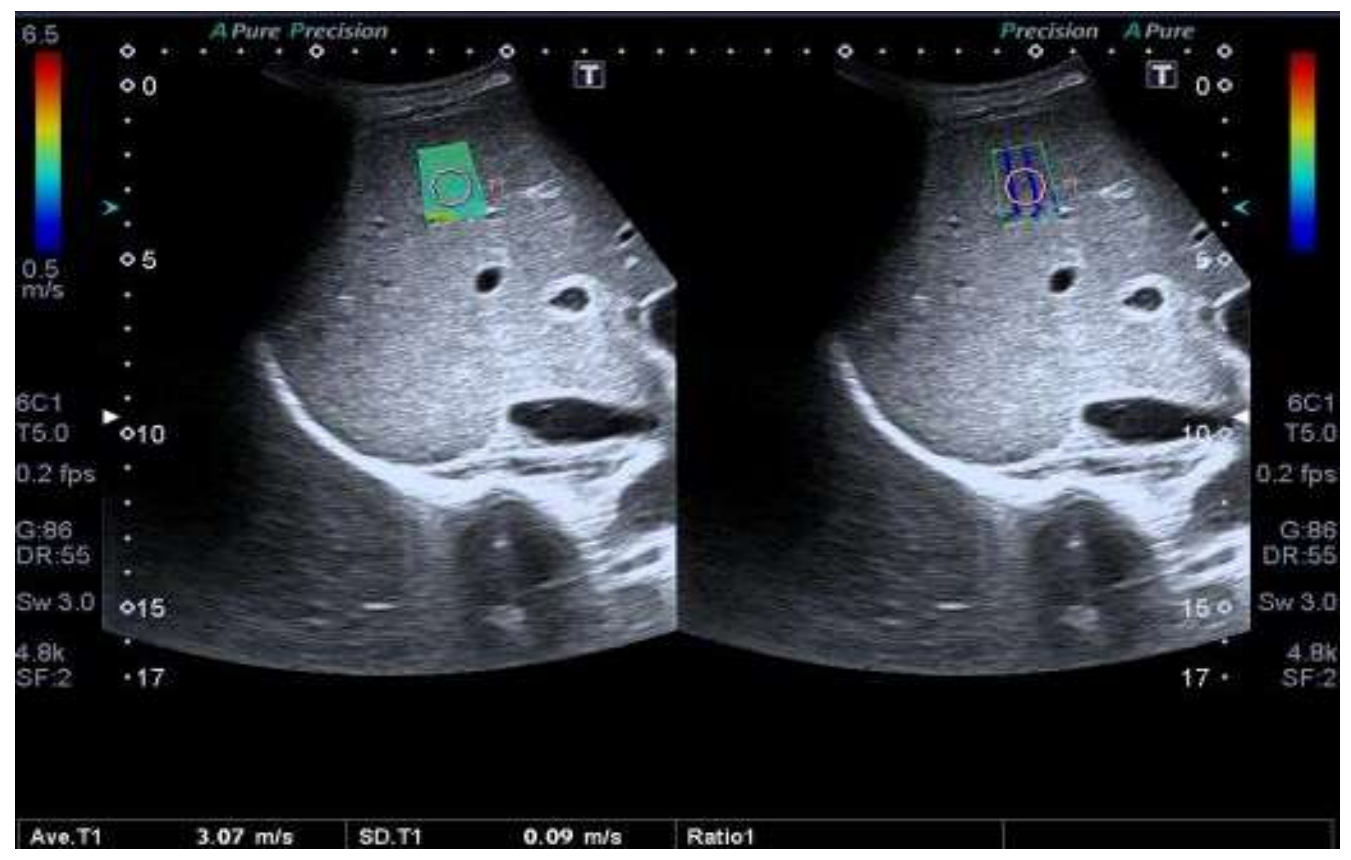

Fig. (4): A 54-year-old patient with chronic hepatitis $C$ and unremarkable $B$ mode liver ultrasound features. 2D shear wave elastography revealed a liver stiffness of $3.07 \mathrm{~m} / \mathrm{s} \pm 0.09$ (F3 according to Metavir scoring). Endoscopy revealed low risk small esophageal varices, whitish in color, with no red color sign (grade II by size criteria) 


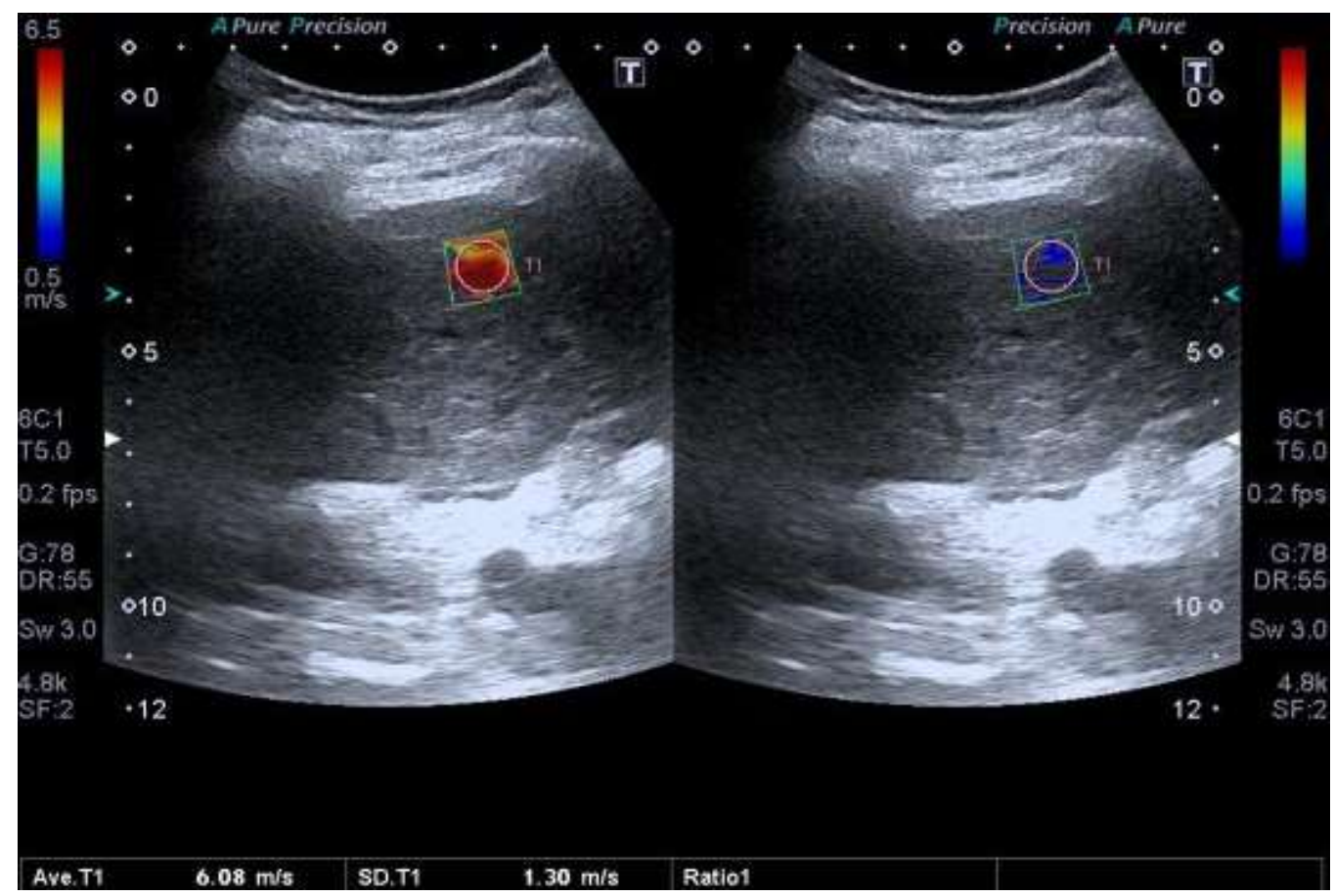

Fig. (5): A 67-year-old patient with chronic hepatitis $\mathrm{C}$ and cirrhotic liver changes by B mode ultrasound. 2D shear wave elastography image showing liver stiffness of $6.08 \mathrm{~m} / \mathrm{s} \pm 1.3$. Endoscopy revealed high risk large cords of esophageal varices, bluish in color with a red color sign (grade III by size criteria).

\section{DISCUSSION}

Routine endoscopic screening for all patients with cirrhotic liver and periodic endoscopy every 2 or 3 years for patients without varices and every 1 year for patients with small varices may be recommended ${ }^{(7)}$. This means that a large proportion of patients should undergo repeated endoscopic examination. In addition to its cost, endoscopy is considered an invasive procedure that may not be acceptable by some patients. Thus, noninvasive alternatives are needed to reduce unnecessary repeated endoscopic procedures ${ }^{(8)}$. Of the different elastographic methods available, those that include B-mode sonograms such as shear wave elastography show a much more benefit because of its ability to ensure an appropriate region of interest, assess for signs of advanced fibrosis, and screen for hepatocellular carcinoma ${ }^{(9)}$.

Portal hypertension develops as a result of an increase of intrahepatic resistance to portal blood flow due to morphologic and biochemical changes associated with liver fibrosis ${ }^{\mathbf{( 1 0})}$, resulting in an increase in liver stiffness.

In this study, we found that the high risk varices group had a significantly higher liver stiffness and AP ratio rather than low risk group with a cut-off value of $2.4 \mathrm{~m} / \mathrm{s}$, liver stiffness measurement by SWE had $75 \%$ sensitivity, $70 \%$ specificity, $71 \%$ PPV and $73 \%$ NPV.

However, other extra-hepatic factors such as hyperdynamic circulation, and splanchnic vasodilatation, as well as development of portosystemic collaterals contribute to the rising portal pressure ${ }^{(\mathbf{1 1})}$. Thus, liver stiffness may not be sufficient for reflecting such complex haemodynamic changes and to distinguish between different grades of esophageal varices. The increased portal pressure and augmented resistance to splenic vein outflow with subsequent splenic vascular congestion and angiogenesis, as well as lymphoid hyperplasia and fibrosis have justified the use of spleen stiffness as another surrogate parameter of portal hypertension $(\mathrm{PH})$.

In this study, spleen stiffness measurement was significantly higher in patients with VNT with a cut-off value of $3.6 \mathrm{~m} / \mathrm{s}$, sensitivity $87.5 \%$, specificity $78.3 \%$, PPV $80 \%$, NPV $86.2 \%$ and accuracy $94 \%$. Takuma $e t$ $\boldsymbol{a l} .^{\left({ }^{(12)}\right.}$ reported high diagnostic performance of SS for the presence of high-risk esophageal varices $(\mathrm{EVs})(\mathrm{AUC}=$ 0.930), which is in agreement with our findings. Results obtained from a meta-analysis by Ma et $\boldsymbol{a l} .{ }^{\mathbf{( 1 3 )}}$ concluded that SS is significantly superior to LS for detection of varices in chronic liver disease (CLD) patients and that SS measurement may help to select those patients who need endoscopic screening. Liver stiffness (LS) reflects only high vascular pressure within the liver parenchyma due to fibrosis, but not the status of portosystemic collaterals secondary to $\mathrm{PH}^{(\mathbf{1 4}, 15)}$. Rifai et al. ${ }^{\left({ }^{(1)}\right)}$ showed that SS measured by acoustic radiation force impulse (ARFI) elastography was inferior to LS for detecting PH $($ AUC $=0.68$ vs. 0.90$)$. Bota et al. ${ }^{(\mathbf{1 7})}$ reported that spleen stiffness as assessed by acoustic radiation force impulse (ARFI) elastography could not predict the presence or severity of esophageal varices. Thus, the diagnostic performance of SS measured using ARFI 
elastography for clinically significant PHT and EVs is still debatable.

In this study, we selected only a homogenous population of patients with compensated cirrhosis to avoid bias occurring in advanced liver disease. This is supported by Lim and Groszmann ${ }^{(14)}$, as they found a plateau effect in advanced fibrosis after which further increase of liver stiffness was not reflected upon portal hyper-tension. Fierbinteanu-Braticevici et al..$^{(18)}$ found that the link between LS and HVPG decreases in severe cirrhosis as a result of the dynamic features of $\mathrm{PH}$. Vermehren et $\boldsymbol{a l}^{\left({ }^{(\mathbf{1 9})}\right.}$ reported significantly low diagnostic performance of SS for predicting large EVs (AUC=0.58). Mori et $\boldsymbol{a l}^{(\mathbf{2 0})}$ postulated that SS significantly correlates with the presence of ascites but not EVs in chronic hepatitis $\mathrm{C}$ patients.

The contradictory findings of different studies may be explained in view of considering varices represent only a part of portal hypertension pathophysiology. The varying cut-off values and different etiologies would be also an important limitation. Technical failure related to SWE, the most important of which is obese patients with BMI $\geq 28$ $\mathrm{kg} / \mathrm{m}^{2}$, is another obstacle, yielding LSM and SSM relevant for only limited subset of individuals.

\section{CONCLUSIONS}

In conclusion, shear wave elastography is an effective and noninvasive tool not only for staging fibrosis, but also for predicting clinically significant portal hypertension. Either liver or spleen stiffness as determined by 2D shear wave elastography can predict patients more likely to have high risk varices, especially in compensated liver cirrhosis, before late stages of disease advancement. Those patients will be in need for endoscopic screening.

Conflicts of Interest: Non-applicable.

\section{REFERENCES}

1. Muir A (2015): Understanding the Complexities of Cirrhosis. Clinical Therapeutics. Excerpta Medica Inc., 37: 1822-36.

2. Biecker E (2013): Portal hypertension and gastrointestinal bleeding: Diagnosis, prevention and management. World Journal of Gastroenterology. WJG Press, 19: 5035-50.

3. Boregowda U, Umapathy C, Halim N et al. (2019): Update on the management of gastrointestinal varices. World J Gastrointest Pharmacol Ther., 10 (1): 1-21.

4. Suk K (2014): Hepatic venous pressure gradient: clinical use in chronic liver disease. Clinical and molecular hepatology. Korean Association for the Study of the Liver, 20: 6-14.

5. Stefanescu H, Procopet B (2014): Noninvasive assessment of portal hypertension in cirrhosis: Liver stiffness and beyond. World J Gastroenterol., 20 (45):
16811-9.

6. Nowicki A, Dobruch-Sobczak K (2016): Introduction to ultrasound elastography. J Ultrason., 16 (65): 113-24 .

7. De Franchis $R$ (2006): Noninvasive diagnosis of esophageal varices: Is it feasible? American Journal of Gastroenterology, 101: 2520-2.

8. Garcia-Tsao G, Sanyal A, Grace N et al. (2007): Prevention and management of gastroesophageal varices and variceal hemorrhage in cirrhosis. Hepatology, 46: 922-38.

9. Sigrist R, Liau J, Kaffas A et al. (2017): Ultrasound elastography: Review of techniques and clinical applications. Theranostics. Ivyspring International Publisher, 7: 1303-29.

10. Iwakiri Y (2014): Pathophysiology of portal hypertension. Clinics in Liver Disease, 18: 281-91.

11. Bolognesi M, Di Pascoli M, Verardo A et al. (2014): Splanchnic vasodilation and hyperdynamic circulatory syndrome in cirrhosis. World J Gastroenterol., 20 (10): 2555-63.

12. Takuma $Y$, Nouso $K$, Morimoto $Y$ et al. (2013): Measurement of spleen stiffness by acoustic radiation force impulse imaging identifies cirrhotic patients with esophageal varices. Gastroenterology, 144 (1): 92-101.

13. Ma X, Wang L, Wu H et al. (2016): Spleen stiffness is superior to liver stiffness for predicting esophageal varices in chronic liver disease: A meta-analysis. PLoS One, 11 (11): e0165786.

14. Lim J, Groszmann R (2007): Transient elastography for diagnosis of portal hypertension in liver cirrhosis: Is there still a role for hepatic venous pressure gradient measurement? Hepatology, 45: 1087-90.

15. Colecchia A, Montrone L, Scaioli E et al. (2012): Measurement of spleen stiffness to evaluate portal hypertension and the presence of esophageal varices in patients with HCV-related cirrhosis. Gastroenterology, 143 (3): 646-54.

16. Rifai $\mathrm{K}$, Cornberg J, Bahr $M$ et al. (2011): ARFI elastography of the spleen is inferior to liver elastography for the detection of portal hypertension. Eur $\mathrm{J}$ Ultrasound, 32 (2): 24-30.

17. Bota S, Sporea I, Şirli R et al. (2012): Can ARFI elastography predict the presence of significant esophageal varices in newly diagnosed cirrhotic patients? Ann Hepatol., 11 (4): 519-25.

18. Fierbinteanu-Braticevici $\mathrm{C}$, Tribus $\mathrm{L}$, Peagu $\mathrm{R}$ et al. (2019): Spleen Stiffness as Predictor of Esophageal Varices in Cirrhosis of Different Etiologies..https://www.nature.com/articles/s41598019-52407-y

19. Vermehren J, Polta A, Zimmermann O et al. (2012): Comparison of acoustic radiation force impulse imaging with transient elastography for the detection of complications in patients with cirrhosis. Liver Int., 32 (5): $852-8$

20. Mori K, Arai H, Abe T et al. (2013): Spleen stiffness correlates with the presence of ascites but not esophageal varices in chronic hepatitis $\mathrm{C}$ patients. Biomed Res Int., 2013:857862. 